\title{
THE ROLE OF VERTICAL INTEGRATION IN INPUT PROCUREMENT
}

\author{
Ratu Farah Nadia \\ Master of Science in International Management \\ Faculty of Business Administration \\ Furtwangen University of Applied Science, Germany
}

\author{
Prof. Dr. Daniel Cerquera \\ Faculty of Business Administration \\ Furtwangen University of Applied Science, Germany
}

In the introduction part this paper review of three methods in input procurement that could be chosen by the firm. As well as in the same chapter elaborate the difficulties that could emerge in implementing of these methods. The aim of this paper is to focused on one of method in input procurement that is vertical integration. The role of vertical integration is implemented by the firm can be addressed to neoclassical theories and organizational theories. Both of these theories are constructed in theoretical framework. In chapter three, this paper elaborate Apple and Samsung which have been successfully in doing vertically integrated. The conclusion is concluded from gathering the related theories and summarizing the application of both successfull companies in achieving their profitability with implemented vertical integration.

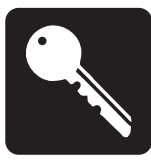

Vertical Integration, Procurement, Profitability. 


\section{INTRODUCTION}

\section{I.1. BACKGROUND}

$\mathrm{I}$ n every firm has an authority to manage the cost. A manager attempt to manage a cost as a minimum amount. All cost in a firm deal with a transaction. Based on theory of Transaction economics, there happen two kind of transaction in every firm. The transaction can be external or internal to an organization. Transactions can occur whenever a good or service is transferred from a provider to a user.

When transactions occur within an organization or firm, the transaction costs will include managing and monitoring personnel and procuring inputs as well as capital equipment. The transaction costs of buying the same good or service from an external provider can include the costs of source selection, contract management, performance measurement and dispute resolution. In this paper will elaborate briefly about the procuring input that happen in the firm. Actually, the manager should acquire inputs in such a way as to minimize costs. The cost minimizing method can depend on the extent to which there is relationship specifically exchange.

There are three kind of method in input procurement. The first method is spot exchange. This method is the easiest way for a firm to obtain inputs in a production process is to use spot exchange. This method could be chosen by a firm if there are no transaction costs happened and there are many buyers and sellers in the input market. So, in this method the manager of the firm can easily gain the input from supplier chosen at randomly by paying per unit of input at price which the market price is determined by the intersection of the supply and demand curves for the input.
For spot exchange we can have a look on the automobile company. The automobile company that used spot exchange method is focusing only on producing something that the company good produce it. But on the other part of goods is producing by other company. In this method the companies give a chance to other company to become their supplier in input their procurement. Due to the companies want to avoid the costs for producing in a specialization of the goods. Although, this method can affect the difficulties and emerge a problem for company itself. I will explain in more detail about the problem that could be happened in every method in next chapter.

The second method in input procurement is contracts. This method is safer and more secure than the first method. This method can control the price of the goods because we already have contract or agreement of the price among the company and the supplier. All of the agreements have been written in the contract. However, this method is more secure to keep minimizing of transaction cost between company and supplier but on the other hand still can appear some problems because of using this method.

The third method in input procurement is using vertical integration. It means that the firm set up a facility to produce the input internally. This method is chosen by the firm because they want to move farther up the production stream toward increasingly basic inputs. For example, most automobile manufactures make their own fenders from sheet steel and plastics, having vertically integrated up the production stream from automobile assembly to the fabrication of body parts (Baye, p. 215). 


\section{I.2. THE DIFFICULTIES OF THESE METHOD IN INPUT PROCUREMENT}

The first method is called spot exchange. In this method there is hold-up problem. It means that the uncertainty situation will be happened anytime. Let make an example according this method to understand easily. Imagine, There is a fast food restaurant that sell burger as its product. The fast food restaurant need 100 beef for produce its burger everyday and the manager of fast restaurant deal with one of supplier beef to input its procurement of beef with delivering the beef everyday in order to produce its products. One day, the supplier of beef desired to make more profit. The supplier attempt to charge higher price for each beef. So, what could be happened for this fast food restaurant to keep producing its burger?.

This illustration above show kind of hold-up problem that could be happened in spot exchange situation. This method can emerge the uncertainty in the transaction cost among a firm and supplier as well as the supplier can take opportunity to charge maximum price for per unit goods. Because in spot exchange there is no agreement that can strongly keep the cost stable. This method is the easiest method for implementing in every firm but on the other hand this method is not secure. The risk could be happened any time.

If the first method does not work out, the firm could take a decision to choose the second method in inputing procurement. The second method is contract. However, this method is much better than the previous method but still could be happened some problem in dealing with the supplier. First possibility that could be happened is the cost in complex environment. It means that everythings is changing because of the environment in market changed. In this method, the firm can not change the price that was already written in contract. Because the firm already made an agreement between the firm and the supplier.

This second method make the firm have a bond with the contract. Even the market price could be changing because of changing in complex environment, but the firm can not change the price until the contract run out. For example, the toys industry has been dealing at certain price in contract 5 years with its supplier from USA to input plastic for its procurement in order to produce the toys. One day, the environment of plastic market is changing from USA as a leader to China. Other toys industries deal with China as a supplier to input their procurement. The reason is because China produce plastic in large quantity and lower price. Unfortunately, in this case the toys industry can not change its supplier to choose another supplier which charge at lower price. Thus, the toys industry have to wait until the contract run out in 5 years later in order to change its supplier.

The other problem that could be happened in bonding contract is the flexibility of contingency. It means that the company have to deal with its supplier at certain period and certain price. In the case toys industry have to charge more costly in inputing its procurement until 5 years because of already bonding with contract, however, the situation of market price has been changing. Although, this second method can 
omit unpredictable situation which appear opportunistic supplier who may charge as a maximum price suddenly but this second method also is still lack in dealing with suppliear for inputing procurement.

The rest method is with vertical integration. This method could be choosen by a manager of the firm if the two method previously, spot exchange and contract, are failed. Vertical integration is the hardest method implemented by the firm. However this method will be very powerful if the company have been succeed in doing integrated vertically for its procurement. In doing vertical integration also have some difficulties. The difficulty is the firm must bear the cost of setting up production facilities for producing that product. Because in being vertical integration the firm is willing to pay a lot of cost in installing and set up everything to be a producer for the different goods that the firm may not expert produce it. So, to get lost and not good quality product is high chanced.

\section{I.3. FOCUSED ON DOING VERTICAL INTEGRATION IN INPUT PROCUREMENT}

As we understand from the previous elaboration, there are some difficulties in doing spot exchange and contract. If both method are failed, the firm will choose the last resort left is doing integrated vertically. vertical integration have been choosen by the firm because to avoid the opportinistic supplier who will charge at a maximum price or attempt to charge at the highest price in order to get maximum profit. In doing vertical integration the firm will produce by the firm itself to fullfil its procurement. The cost for producing one of unit product will exactly visible by the firm itself.

Considerable resources are spent on attorney's fees and bargaining over contract terms that can drive the firm to choose in doing vertical integration. Due to avoid the complex contracting environment which it is not efficient to write longer contracts to reduce these costs. Faced with those prospects, the manager of the firm may wish to use yet another method to produce a necessary input. The method that would choose by the firm is having integrate vertically for the input with making the input it self.

The aims of this term paper is to elaborate briefly about one of method in inputing procument in the firm or organization in order to focus on one method that can be the best role for inputing procurement of the company. In this paper will elaborate the role of vertical integration in connecting with the theory that has been taught by Prof. Kirner in her last lecture. The theory are neoclassical theory and organizational theory in implementing vertical integration. Those theory will elaborate briefly in the following theoritical Framework.

\section{THE ORITICAL} FRAMEWORK FOR VERTICAL INTEGRATION

\section{II.1. OPTIMAL INPUT PROCUREMENT}

Firstly, let me make summary regarding on the introduction part about the three method in achieving optimal input procurement. The summary is constructed with the following graph. 
Figure 1: Advantages and Disadvantages of Three method in input procurement.

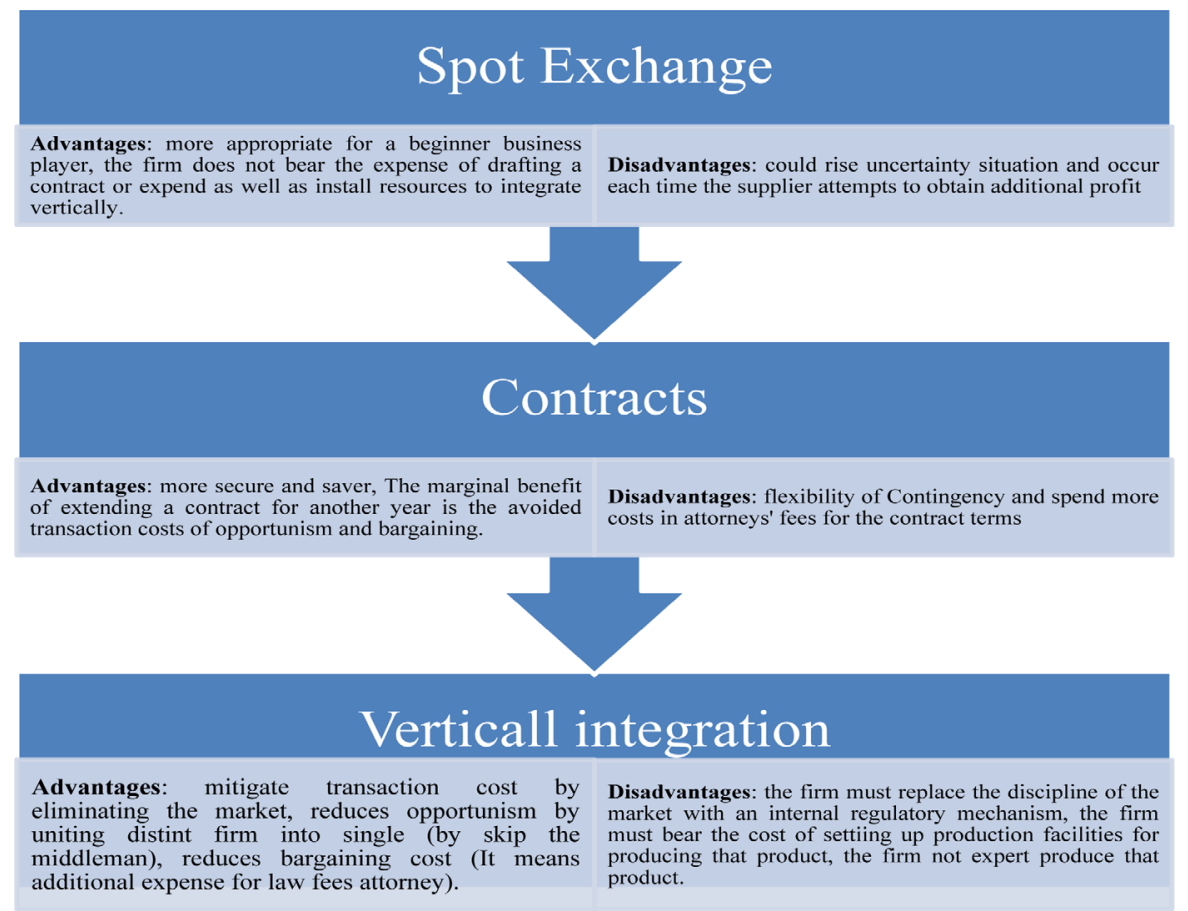

Source: Managerial Economics and Business Strategy, 7th edition, Michael R. Baye, Modified

For minimizing cost could be acquired with input procurement using one of those methods above. The decision is depend on the firm itself which one would be necessary to use. Whether a manager chooses spot exchange or an alternative method such as a contract or vertical integration depends on the importance of the specialized investment that lead to relationship-specific exchange (Baye, $\mathrm{p}$. 216).

\section{II.2. VERTICAL INTEGRATION APPROACH ON NEOCLASSICAL THEORY}

According to Paul L. Joskow (2005) in his paper, he involved the two alternative economic theories of vertical integration. The first theory is Neoclassical theories of vertical integration. This theory drive on efforts of firms either to mitigate inefficiencies caused by market power at one or more levels of the vertical chain or to create or enhance market power at one of both levels. The second theory is Organizational theories of vertical integration. This second theory focused on inclomplete contracts, assest specificity, information imperfections, opportunistic and the costs of internal organization. These following theories address to focus on efforts by firm in mitigating transaction costs and various contractual hazards.

Neoclassical approaches to vertical integration have tended to focus primarily on vertical integration as a response to pre-existing market prower problem in upstream or downstream markets (Joskow, 2005). Regarding on neoclassical theory there are some factors that could determine the boundaries between firms and markets were largely ignored and issues associated with the internal organization of firms and the way firms allocated resources internally (Joskow, 2005). Neoclassical concept encourage firms 
to conceptualize as a production sets that defined the technologically most efficient opportunisties to transform input into outputs.

\section{II.3. VERTICAL INTEGRATION APPROACH ON ORGANIZATIONAL THEORY}

Based on economic research that vertical integration theoritical framework from broader organizational cost or benefit perspective involved into two interrelated perspectives: firstly is transaction cost economic theories and property rights or control rights theories (Joskow, 2005). According to Joskow in his paper, the foundation of transaction cost economics theories and property rights theories of vertical integration is:

"The recognition that contracts are incomplete and that contractual incompleteness potentially leads to contractual hazards that adversely affect ex-ante investment incentives and the efficiency of ex-post performance".

The contractual incompleteness and the interaction can drive the contribution of different types of transactional attributes including asset specify, complexity and uncertainty, as well as plays a central role in the evaluation of the relative costs of governance through market-based bilateral contracts versus governance through vertical integration (Joskow, 2005).

The research literature formally show the Coasen logic that in the absence of transaction costs can replicate the economic advantages of vertical integration (Mahoney, 1992). Therefore, the formulation of vertical integration strategies requires consideration of governance structures to implement business objectives (such as increasing revenues, decreasing costs, and reducing risks in ways that cannot be easily replicated by shareholders) (Harrigan, 1984). The transaction costs research literature is that the particular governance structure choosen to implement the strategy of vertical integration primarily serves efficiency purposes (Williamson, 1991).

In contractual difficulties arise when opportunistic agents engage in frequent transactions in an environment of sufficient uncertainty and complexity that surpass bounded rationality capabilities (Simon, 1978). In addition, it is important to highlighted that environmental uncertainty and complexity, which can lead to incomplete contracting when relationship specifically in investments surround an exchange (Williamson, 1985).

On the one hand there is the potential advantages of vertical integration address to internal organizational in allocating mechanism. The allocation mechanism are likely to achieve better condition in order to harmonize these conflicting interests and provide for smoother and less costly as well as more efficient adaptation to change supply and demand condition over time (Williamson, 1985). As Williamson also mentioned in his paper (1971, pp. 116$117)$ that observed many years ago:

“... The contractual dilemma is this: on the one hand, it may be prohibitively costly, if not infeasible, to specify contractually the full of contingencies and stipulate appropriate responses between stages. On the other hand, if the contract is seriously inclomplete in these respects but, once original negotiations are settled, the contracting parties are locked into a bilateral exchange, the divergent interests between the parties will predictably lead to individually 
opportunistic behaviour and joint losses. The advantages of integration thus are not that technological (flow process) economies are unavailable to nonintegrated firms, but that integration harmonizes interests and permits an efficient (adaptive, sequential) decision process to be utilized...".

Regarding on the quotation above that take a look from Williamson's research paper can conclude that it means there is interaction between contractual incompleteness and certain attributes of transactions (Joskow, 2005). This interaction according to Joskow can lead the firm to a trading relationship to become "locked-in" to the relationship once the relationship is consummated. According to Joskow research paper as well, he mentioned that there is relationship among contractual incompleteness and specific investment:

"....when they are required to support an efficient trading relationship, have come to play a central, through not exclusive, role in creating bilateral trading relationships that are susceptible to ex post bargaining and contractual performance problems. Relationship-specific investments are investments which, once made, have a value in alternative uses that is less than the value in the use originally intended to support a specific trading relationship. once specific investments have been made a potential hold-up or opportunism situation is created if the parties can bargain over..."

This, in this theory conclude that vertical integration is favored when the benefits of mitigating opportunism problems that may arise as a consequence of specific investment will be greater than the costs of other static and dynamic infficiency that may be associated with resource allocation (Joskow, 2005). Regarding on the organizational economies literature there are some benefits and costs of vertical integration. The market transaction will incur transactions costs associated with writing and enforcing continget contracts and the inneficiencies could arise in resulting from opportunistic behaviour that exploits specific investments. On the other hand, the internal bureaucratic allocation may be used as a consequence of vertical integration which can help to mitigate the types of transaction costs.

\section{APPLICATION OF VERTICAL INTEGRATION}

In this part this paper will take an one application of doing vertical integration. Samsung electronics and Apple are two largest technology firms in knowdays. Both companies provide a new paradigm on how vertically integrated today operate. This business model allows Samsung and Apple to gather their proficiencies at same time and their primary objective is to minimize transaction costs. Let me introduce firstly what has Apple been done so far in doing vertical integration.

The introduction of a new computer operating platform clearly demonstrates Apple's prowess in innovation. The launching of iPad can provide an excellent example of how a company can build competencies using backward and forward integrations. Connecting with theory in previous chapter conclude that integration are implemented for a 
number of reason; extent our capabilities by controlling inventory quality, timing, and availability; improving distribution channels; utilizing enhancements in technology and innovation to extend our competitive advantage.

In this case, Apple has pursued both backward and forward integration by controlling the manufacturing of its hardware, both computer chips and devices (Bajarin, 2011). It means that Apple can control the innovation supply chain and by knowing its customers best can apply its knowledge of customer experience and maintain its control. Apple has an objective that quality is a key characteristic for innovative as instilling pride of its products become paramount when customers have the ability to buy successive generations of the product.

Apple is going to continue with the backward and forward integration model as it has served them well. On the other hand, there is a challenge for Apple in doing both those integration. The challenge that Apple has going forward is the development of competition of the same device platform and content generation (Bajarin, 2011). In addition, Apple can continue its market presence as it has a proven track record to continually introduce new generations of their product and does so by leveraging their unique ability in product innovation. Therefore, the competencies that integration provides are the reuse of their Apple software components among its portfolio of products.

In polar case, Samsung electronics is doing also vertically integrated as a specialized supplier. So, It drives Samsung to be able to achieve economic scale. Samsung can allow to hold on to its position as a cusumer electronics giant by leveraging on its ability in producing component parts and assemble its products on a large scale and cost efficient process. Samsung "operates using a vertical integration model which leverages all aspects of the manufacturing process from raw materials to electronics components to fully-assembled products" (Eisenberger, Li, Mitrenko, Vajrapu and $\mathrm{Xu}, 2003$ ). According on research paper by Yoo-chul (2010), Samsung electronics is also one of the world's largest suppliers of electronics components.

Recently, both these largest companies have competed in producing smartphone sector. Both Samsung and Apple gained profit from unique structure and their customer relationship (Vergara, 2012). According to Cacciatory and Jacobides (2005) paradigm both Samsung and Apple have done reintegrating some of its vertical chains. Therefore, They are able to protect their possibilities, enter new and related markets and find new ways of leveraging capabilities.

\section{CONCLUSION}

Vertical integration can be interpreted as forward integration by an upstream supplier to acquire the property rights of the downstream buyer. In vertical integration; the asset specificity, bounded rationality and opportunism conspire to undermine efficient investments. This decision is chosen by the firm due to incomplete contracting causes a hold up problem that diminishes the investment incentive of the party lacking control rights. According to theoretical framework have been elaborated in previous chapter, 
the firm add vertical integration due to may cause investment distortions motivated by the pursuit of a bargaining advantage. In such circumstances, the distortions arising from vertical integration raise expected production costs. Nevertheless, a vertical integration acquisition may be a profitable strategy because it squeezes the profits of the remaining external suppliers.

In application of doing vertical integration both Apple and Samsung can continue to be vertically integrated, but still able to specialize and leverage on their core competencies. By doing vertically integrated, both companies are able to maintain their product chain where they are good at, addressing them to reach economies of scale and profitability. Here, these following graphs summarized of action for both companies in doing vertical integration.

\section{Figure 2: Samsung's Vertical} Integration

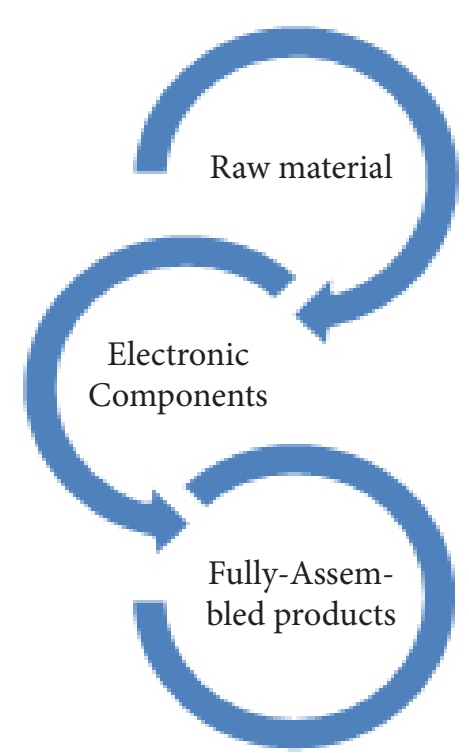

Source: Raymond Allan G.Vergara, American International Journal of Contemporary Research, vol. 2, No. 9, September 2012, p. 79.
Figure 3: Apple's Vertical Integration

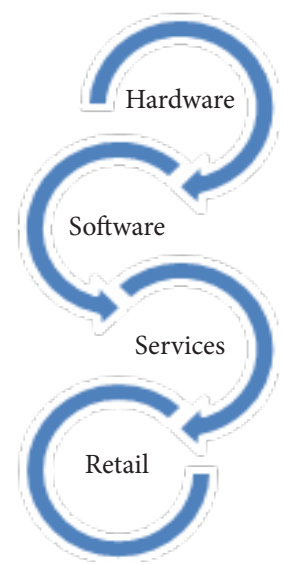

Source: Raymond Allan G.Vergara, American International Journal of Contemporary Research, vol. 2, No. 9, September 2012, p. 80.

\section{REFERENCES}

Bajarin, B. (2011, July 1). Why Competing with Apple Is So Difficult. Time.

Cacciatori, E.and Jacobides, M.G (2005). The Dynamic Limits of Specialization: Vertical Integration Reconsidered. Organization Studies, 26(12),1851-1883.

Eisenberger, C., Li, X., Mitrenko, A., Vajrapu, K. and Xu, L. (2003). Samsung Electronics Company.

Michael D, Whinston 2003, 'On the Transaction Cost Determinants of Vertical Integration', Oxforf University Press, Nortwestern University and NBER, Journal of Law, Economics and Organization, Vol. 19, no.1.

Michael R, Baye, 7th Edition, 'Managerial Economics and Business Strategy', pp. 210-216.

Paul, L, Joskow 2006, 'Vertical integration', Revised revision 5 December 2006, Massachusetts Institute of Technology. 
Paul, L, Joskow 1998, 'Asset Specificity and Vertical Integration', working paper, Massachusetts Institute of Technology.

Paul, L, Joskow 2005, 'Vertical Integration', working paper, Massachusetts Institute of Technology.

Raymond Allan G, Vergara 2012, American International Journal of Contemporary Research, vol. 2, No. 9, pp. 77-80.

Simon, Loertscher, Michael, Riordan 2011, ' Procurement, Cost reduction and vertical integration', University of Melbourne working paper.

Valdez, E. (2012, February 3).Apple, Samsung Top Profit and Sales. Technorati.

Williamson, Olliver, E 1979, 'Transaction of Economics: the governance contractual relations', Journal of Law and Economics, vol. 22, pp. 233-262.

Yoo-chul, K. (2010, June 6). Sony, Apple, Dell are Samsungs big buyers. The Korea Times.

Eisenberger, C., Li, X., Mitrenko, A., Vajrapu, K. and Xu, L. (2003). Samsung Electronics Company.

Michael D, Whinston 2003, 'On the Transaction Cost Determinants of Vertical Integration', Oxforf University Press, Nortwestern University and NBER, Journal of Law, Economics and Organization, Vol. 19, no.1.
Michael R, Baye, $7^{\text {th }}$ Edition, 'Managerial Economics and Business Strategy', pp. 210-216.

Paul, L, Joskow 2006, 'Vertical integration', Revised revision 5 December 2006, Massachusetts Institute of Technology.

Paul, L, Joskow 1998, 'Asset Specificity and Vertical Integration', working paper, Massachusetts Institute of Technology.

Paul,L,Joskow2005, 'VerticalIntegration', working paper, Massachusetts Institute of Technology.

Raymond Allan G, Vergara 2012, American International Journal of Contemporary Research, vol. 2, No. 9, pp. 77-80.

Simon, Loertscher, Michael, Riordan 2011, ' Procurement, Cost reduction and vertical integration', University of Melbourne working paper.

Valdez, E. (2012, February 3).Apple, Samsung Top Profit and Sales. Technorati.

Williamson, Olliver, E 1979, 'Transaction of Economics: the governance contractual relations', Journal of Law and Economics, vol. 22, pp. 233-262.

Yoo-chul, K. (2010, June 6). Sony, Apple, Dell are Samsungs big buyers. The Korea Times. 